\title{
Correction: Tumor volume improves preoperative differentiation of prolactinomas and nonfunctioning pituitary adenomas
}

\section{Kyla Wright ${ }^{1} \cdot$ Matthew Lee $^{2} \cdot$ Natalie Escobar ${ }^{1} \cdot$ Donato Pacione $^{3} \cdot$ Matthew $_{\text {Young }}{ }^{2} \cdot$ Girish Fatterpekar $^{2}$. Nidhi Agrawal ${ }^{4}$}

Published online: 5 July 2021

(c) Springer Science+Business Media, LLC, part of Springer Nature 2021

Correction to: Endocrine

https://doi.org/10.1007/s12020-021-02744-8

In this erratum the * sign has been included for the following authors Kyla Wright and Matthew Lee to indicate the first co-authors.
In the abstract the CSI has been defined to "cavernous sinus invasion".

The Original article has been updated.

The original article can be found online at https://doi.org/10.1007/ s12020-021-02744-8.

$\triangle$ Nidhi Agrawal

Nidhi.agrawal@nyulangone.org

1 NYU Grossman School of Medicine, NYU Langone Health, 550 1st Ave, New York, NY 10016, USA

2 Department of Radiology, NYU Langone Medical Center, 550 1st Avenue, New York, NY 10016, USA

3 Department of Neurosurgery, NYU Langone Medical Center, 1st Avenue, New York, NY 10016, USA

4 Division of Endocrinology, Diabetes and Metabolism, NYU Langone Medical Center/ Bellevue Hospital Center, 550 1st Avenue, New York, NY 10016, USA 